\title{
Chronic immune activation associated with intestinal helminth infections results in impaired signal transduction and anergy
}

\author{
Gadi Borkow, ${ }^{1}$ Qibin Leng, ${ }^{1}$ Ziva Weisman, ${ }^{1}$ Miguel Stein, ${ }^{1}$ Noya Galai, ${ }^{2}$ \\ Alexander Kalinkovich, ${ }^{1}$ and Zvi Bentwich ${ }^{1}$ \\ ${ }^{1}$ R. Ben-Ari Institute of Clinical Immunology and AIDS Center, Kaplan Medical Center, \\ Hebrew University Hadassah Medical School, Rehovot, Israel \\ ${ }^{2}$ Department of Epidemiology, Ben-Gurion University, Beer-Sheba, Israel \\ Address correspondence to: Zvi Bentwich, R. Ben-Ari Institute of Clinical Immunology, AIDS Center, \\ Kaplan Medical Center, Rehovot 76100, Israel. Phone: 972-8-9441444; Fax: 972-8-9410461; E-mail: bentwich@agri.huji.ac.il.
}

Gadi Borkow and Qibin Leng contributed equally to this work.

Received for publication April 28, 2000, and accepted in revised form September 12, 2000.

\begin{abstract}
Helminthic parasites cause widespread, persistent infections in humans. The immigration of Ethiopians to Israel (a group denoted here by "Eth."), many of them infested with helminths and in a chronic immune-activation state, enabled us to investigate the effects of such immune activation on immune responses. We studied the immune profile and immune functions of $190 \mathrm{Eth}$. and Israeli non-Eth. (Isr.) highly, partially, or non-immune-activated individuals. Immune cells from highly immune-activated individuals were defective in several signaling responses, all of which were restored gradually following anti-helminthic treatment. These cells showed poor transmembrane signaling, as seen by the phosphorylation of various tyrosine kinases and of the MAPK kinases, ERK1/2 and p38; deficient degradation of phosphorylated I $\mathrm{K} B \alpha$; increased expression of cytotoxic T lymphocyte-associated antigen 4 (CTLA-4), which appears to block proliferative responses in these cells; decreased $\beta$-chemokine secretion by $\mathrm{CD}^{+}$cells after stimulation; and reduced proliferation to recall antigen stimulation. Highly immune-activated individuals also showed decreased delayed-type skin hypersensitivity responses to recall antigen before deworming. These findings support the notion that chronic helminthic infections cause persistent immune activation that results in hyporesponsiveness and anergy. Such impaired immune functions may diminish the capacity of these individuals to cope with infections and to generate cellular protective immunity after vaccination.
\end{abstract}

J. Clin. Invest. 106:1053-1060 (2000).

\section{Introduction}

Helminthic infections are common in vast regions of the world, especially in the developing countries, and by the most conservative estimates, they affect more than a quarter of the world's population (approximately 1.5 billion people) (1). In addition, millions of individuals in the developing countries also have other chronic infectious diseases, such as malaria, tuberculosis (TB), protozoa, and HIV $(2,3)$. These infections lead to persistent activation of the immune system, and thus vast populations in the globe, especially in Africa and Asia, are in a chronic immune-activation state. However, how chronic immune activation affects the capacity of the immune system to respond to stimuli is not well understood.

During the last 15 years, about 60,000 Ethiopian Jews emigrated from Ethiopia to Israel. A very high prevalence of several infectious diseases, particularly helminthic infections, has been found among the population of Ethiopian immigrants to Israel (denoted here by "Eth.") (4). More than $80 \%$ of the Eth. individuals were infected with at least one helminthic par- asite, $40 \%$ were infected with two parasites, and some $(\sim 3 \%)$ were even infected with four intestinal helminthic parasites. Although Eth. individuals who immigrated $10-15$ years ago were not infected with HIV, almost $10 \%$ of the Eth. individuals who immigrated during the last year were HIV-1 seropositive (data not shown). All Eth. individuals arrived from areas in which TB is endemic; however, the prevalence of TB was relatively low $(<1.5 \%)(4)$.

Examination of the immune profile of the HIVseronegative, Mycobacterium tuberculosis-noninfected members of the Eth. group revealed a wide immune dysregulation characterized by a dominant Th2 type of cytokine immune response, high IgE levels, eosinophilia, low $\mathrm{CD}^{+}$and high $\mathrm{CD}^{+}$cells, increased HLADR-positive cells in all examined T-cell subsets, decreased proportion of naive $\mathrm{CD}^{+}$cells, and increased proportion of $\mathrm{CD}^{+}$memory cells (5-7). This immune dysregulation, caused mainly by helminthic infections $(6,7)$, is assumed to be widespread in Ethiopia and in other parts of Africa where helminthic infections are endemic. Indeed, similar immune profiles were 
observed in other populations from Ethiopia (8) and other developing countries (9-13). After their arrival in Israel, most Eth. individuals were cured of the helminthic infections (ref. 14; data not shown) and their immune systems slowly returned to normal $(7,15)$.

In the present report, we studied the immune-activation status and the capacity of PBMCs to respond to various stimuli in three groups: recently arrived Eth. individuals (new-Eth.) with helminthic infection before deworming, Eth. individuals living in Israel for at least 3 years (old-Eth.) without helminthic infection after anti-helminthic treatment, and healthy noninfected Israeli-born (Isr.) individuals. In the study, we determined (a) expression of costimulatory and downregulatory receptors on T cells (CD28 and cytotoxic T lymphocyte-associated antigen 4 [CTLA-4], respectively); (b) intracellular events that occur immediately after Tcell stimulation (signal transduction); (c) long-term outcome events, such as proliferation after recall antigen stimulation, and $\beta$-chemokine secretion by $\mathrm{CD}^{+}$ cells; and (d) delayed-type skin hypersensitivity (DTH) responses to recall antigens.

The results of this study clearly show that chronic immune activation results in hyporesponsiveness, manifested by impaired T-cell signal transduction, significantly lower expression of CD28 with concomitant increased expression of CTLA-4, decreased $\beta$ chemokine secretion, low proliferation to recall antigens, and decreased DTH responses.

\section{Methods}

Human subjects. A total of 151 Eth. and 31 Isr. individuals were studied; 111 of the Eth. subjects had been in Israel for fewer than 12 months and did not receive anti-helminthic treatment at the time of their examination. More than $80 \%$ of them were heavily infested by one or more helminthic parasite, as determined by stool examination. Forty-eight Eth. subjects had been living in Israel 3-10 years, and although they received anti-helminthic treatment, in the stool of about $15 \%$ of them, we found a few eggs of Schistosoma mansoni or Trichuris trichuria. All Isr. subjects were free of helminthic parasites, and all individuals were HIV-seronegative as determined by ELISA (Abbott Gmbl Diagnostika, Weisbaden, Delkenheim, Germany).

Cell preparations and cultures. PBMCs, isolated from heparinized blood by standard centrifugation over Histopaque (Sigma, Rehovot, Israel), washed and resuspended in RPMI 1640 medium supplemented with $10 \%$ heat-inactivated human $A B$ serum (Sigma), $2 \mathrm{mM}$ L-glutamine, penicillin, streptomycin, and nystatin (Biological Industries Co., Beit-Haemek, Israel), were cultured at $37^{\circ} \mathrm{C}$ under $5 \% \mathrm{CO}_{2}$. PBMCs $\left(10^{5}\right.$ cells $/ 200 \mu \mathrm{l}$ ), cultured in 96-well plates (CorningCostar, Corning, New York, USA) for 6 days in the presence of $5 \mu \mathrm{g} / \mathrm{ml}$ tuberculin purified protein derivative (PPD) (Statens Serum Institute, Copenhagen, Denmark), with or without $0.66 \mu \mathrm{g} / \mathrm{ml}$ anti-CTLA-4 Fab mAb (Serotec Ltd., Oxford, United
Kingdom), were pulsed with $1 \mu \mathrm{Ci}\left[{ }^{3} \mathrm{H}\right]$ thymidine (Amersham Pharmacia Biotech, Little Chalfont, Buckinghamshire, United Kingdom). Sixteen hours later, the cells were harvested on Whatman 934-AH glass microfiber filters (Whatman International, Maidstone, United Kingdom), and the radioactivity was measured by a Packard Tri-Carb $300 \beta$-counter (Packard Instrument Co., Meriden, Connecticut, USA). Cells cultured in the presence of medium only served as control. All experiments were done in triplicate, and the results are expressed as stimulation index (SI; mean cpm obtained with PPD stimulation/mean cpm obtained for control). The CTLA Fab $\mathrm{mAb}$ 's were prepared from IgG mAb by papain digestion and separation of the Fab fragments with a Centricon concentrator (Amicon Inc., Beverly, Massachusetts, USA). The effectiveness of digestion was verified by SDS gel electrophoresis. To measure the production of chemokines, $\mathrm{CD}^{+}$cells $\left(3 \times 10^{6}\right)$ were separated from PBMCs $\left(\sim 10 \times 10^{6}\right)$ by positive selection using anti-CD8 immunomagnetic beads and miniMACS columns according to the manufacturer's instructions (Miltenyi Biotec GmbH, Beryisch-Gladbach, Germany). Purity of enriched $\mathrm{CD}^{+}$cells was greater than $95 \%$, as determined by flow cytometry. The cells were stimulated with $1 \mu \mathrm{g} / \mathrm{ml}$ PHA (Difco Laboratories, Detroit, Michigan, USA) and $20 \mathrm{ng} / \mathrm{ml}$ PMA (Sigma) for 48 hours. ELISA kits for human MIP- $1 \alpha$ and RANTES were used for determining chemokine levels in the supernatants according to manufacturer's instructions (R\&D Systems, Minneapolis, Minnesota, USA).

Lymphocyte phenotype analysis. One-, two-, or triplecolor immunophenotyping of whole blood or PBMC was performed by FACS (Becton-Dickinson Immunocytometry, San Jose, California, USA) by using one, two or three of the following mAb's conjugated with FITC, PE, or peridin chlorophyll protein (PerCP): CD3, CD4, CD8, HLA-DR, CD45RA, CD45RO (DAKO A/S, Glostrup, Denmark), and CD28 (Becton-Dickinson Immunocytometry). Intracellular expression of CTLA-4 with PE-conjugated mouse anti-human CD152/CTLA-4 mAb (PharMingen, San Diego, California, USA) in $\mathrm{CD}^{+}$cells was performed with the Ortho Permeafix reagent (Ortho Diagnostic Systems Inc., Raritan, New Jersey, USA) according to the manufacturer's instructions. Cells incubated with FITC-, PE-, or PerCP-conjugated mouse IgG1/IgG2a (DAKO) served as isotype controls. A minimum of 10,000 cells per sample was analyzed.

Cell extracts. PBMCs $\left(2 \times 10^{6}\right.$ cells $)$ in $1 \mathrm{ml}$ of RPMI medium were stimulated with $1 \mu \mathrm{M}$ Ca-ionophore A23187 (Sigma) and $10 \mathrm{ng} / \mathrm{ml}$ PMA. At various time intervals after stimulation, the cells were washed with cold PBS and resuspended in $50 \mu \mathrm{l}$ of cold $10 \mathrm{mM}$ HEPES buffer ( $\mathrm{pH}$ 7.6) containing $10 \mathrm{mM} \mathrm{KCl}, 1 \mathrm{mM}$ DTT, $1 \mathrm{mM}$ EDTA, $0.1 \mathrm{mM}$ EGTA, $2 \mathrm{mM} \mathrm{Na}_{3} \mathrm{VO}_{4}, 2$ $\mathrm{mM}$ PMSF, $5 \mu \mathrm{g} / \mathrm{ml}$ leupeptin, $0.3 \mathrm{U} / \mathrm{ml}$ aprotinin, 5 $\mu \mathrm{g} / \mathrm{ml}$ pepstatin, and $20 \mathrm{mM} \beta$-glycerophosphate. After 
15 minutes of incubation on ice, NP-40 was added to the cells to a final concentration of $0.6 \%$, and the cells were incubated on ice for an additional 5 minutes. The mixture was then centrifuged at $21,000 \mathrm{~g}$ at $4^{\circ} \mathrm{C}$, and the supernatant was kept at $-20^{\circ} \mathrm{C}$ until tested. When cell extracts were prepared for examination of phosphorylation of IKB, the cells were incubated for 90 minutes with $150 \mu \mathrm{M} \quad \mathrm{N}$-acetyl-Leu-Leu-norleucinal (ALLN) before their stimulation. All used reagents were obtained from Sigma.

Antibodies and immunoblotting. Aliquots of the cytosolic extracts (corresponding to $\sim 7 \times 10^{5}$ cells) were electrophoreses on SDS-10\% polyacrylamide gels and transferred to nitrocellulose blotting membrane (BioTrace NT; Gelman Sciences, Ann Arbor, Michigan, USA). The membranes were incubated with the primary $\mathrm{Ab}$ for 1 hour at room temperature or overnight at $4^{\circ} \mathrm{C}$ and then blocked for at least 1 hour with 5\% skim milk (Fluka BioChemika, Buchs, Switzerland). The membranes were then incubated for 1 hour at RT with anti-mouse or anti-rabbit HRP Ab and analyzed by using the chemiluminescent SuperSignal substrate according to the manufacturer's instructions (Pierce Chemical Co., Rockford, Illinois, USA). The following primary and secondary antibodies were used in immunoblotting at the dilutions indicated: rabbit anti-IкB $\alpha(1: 2,500$; a kind gift from Y. Ben-Neriah, Hebrew University, Jerusalem, Israel); $\mathrm{mAb}$ antip42/44 mitogen-activated protein kinases/extracellular signal-regulated (MAPK/ERK) and $\mathrm{mAb}$ antiphosphorylated p42/44 MAPK/ERK Ab (1:10,000; both a generous gift from R. Seger, Weizmann Institute, Rehovot, Israel); anti-BCL2 Ab (1:500; DAKO $\mathrm{A} / \mathrm{S}) ; 4 \mathrm{G} 10 \mathrm{mAb}$ antiphosphotyrosine $\mathrm{Ab}$ (1:1,000; Upstate Biotechnology Inc., Lake Placid, New York, USA); and anti-mouse IgG HRP conjugate $(1: 3,000)$ were purchased from Promega Corp. (Madison, Wisconsin, USA); $\mathrm{mAb}$ anti-diphosphorylated p38 MAP kinase $\mathrm{Ab}(1: 1,000)$ and HRP-conjugated anti-rabbit $\operatorname{IgG}(1: 10,000)$ were all purchased from Sigma.

PPD skin test. DTH tests against PPD were carried out by intracutaneous administration, in the flexor surface of the forearm, of 5 tuberculin units $(0.1 \mathrm{ml})$ of the standard strength tuberculin test (Mantoux, Tubersol; Connaught Laboratories Ltd., Toronto, Ontario, Canada). The PPD DTH test is carried out routinely in the Kaplan Medical Center.

Statistical analysis. Statistical analysis of the data was carried by using SigmaStat for Windows Statistical Software (version 2.0; Jandel Scientific, Chicago, Illinois, USA). Spearman Rank correlations, Mann-Whitney rank sum tests and McNemar's $\chi^{2}$ tests were used to analyze the data and compare the groups.

\section{Results}

Immune profile of the studied population. The immune profile of 111 new-Eth., 48 old-Eth., and 31 Isr. individuals (summarized in Table 1) revealed a clear dysregulation of several immune parameters in the new-Eth. group compared with the Isr. group. Such wide dysregulation is similar to that observed previously by us in other new-Eth. individuals (5-7). In contrast, the differences between the old-Eth. group and the Isr. group are not so remarkable (Table 1), demonstrating that the immune profiles of the Eth. individuals return gradually to normal after their immigration to Israel.

For further analysis, and for the sake of simplicity, we divided the examined individuals into three categories of activation, according to the proportion of HLA-DR ${ }^{+}$cells within the $\mathrm{CD}^{+}$cell population and the proportion of $\mathrm{CD}_{28} 8^{+}$cells within the $\mathrm{CD}^{+}$cell population. Nonactivated (NA) individuals were defined as those having a normal percentage of HLA$\mathrm{DR}^{+} / \mathrm{CD}^{+}$and $\mathrm{CD} 28^{+} / \mathrm{CD}^{+}$cells (similar to that of the Isr. group, i.e., $<9 \% \mathrm{HLA}-\mathrm{DR}^{+} / \mathrm{CD}^{+}$cells and $>40 \%$ $\left.\mathrm{CD} 28^{+} / \mathrm{CD}^{+}\right)$. Highly activated (HA) individuals were defined as those having more than 9\% HLA$\mathrm{DR}^{+} / \mathrm{CD}^{+}$cells and less than $40 \% \mathrm{CD} 28^{+} / \mathrm{CD}^{+}$, whereas partly activated (PA) individuals were defined as those having either $\mathrm{HLA}-\mathrm{DR}^{+} / \mathrm{CD}^{+}$or $\mathrm{CD} 28^{+} / \mathrm{CD}^{+}$subsets above or below the normal range, accordingly. All members of the Isr. group were NA, and members of the new-Eth. group were either HA or PA. About $35 \%$ of the old-Eth. group were NA, while the rest were still PA.

Correlation between activation, naive and memory cells, expression of CD28 costimulatory molecules, and the number of $\mathrm{CD}^{+}$cells. We have previously suggested that the decreased CD4 levels and significantly lower CD4/CD8 ratio in the new-Eth. group, compared with the Isr. group, is a consequence of immune activation (5-7). Correlation studies between different immune parameters of the examined Eth. population in the present study strongly supports this hypothesis. For example, individuals with higher percent of $\mathrm{HLA}-\mathrm{DR}^{+} \mathrm{CD} 4^{+}$cells had less $\mathrm{CD}^{+}$cells in the peripheral blood, lower $\mathrm{CD} 4 / \mathrm{CD} 8$ ratio, lower percentage of $\mathrm{CD} 28^{+} \mathrm{CD} 88^{+}$, naive $\left(\mathrm{CD} 45 \mathrm{RA}^{+}\right)$cells, and higher percentage of memory $\left(C D 45 \mathrm{RO}^{+}\right)$cells (Figure 1). Similar correlations between HLA-DR expression on $\mathrm{CD}^{+}$and $\mathrm{CD}^{+}$cells and the various immunological markers examined were also found (data not shown).

Signal transduction studies. Physiological activation of T-lymphocytes requires costimulation through the Tcell receptor/CD3 complex and CD28, which can be mimicked by PMA in combination with $\mathrm{Ca}^{2+}$ ionophore (16-18). After such costimulation, a cascade of phosphorylations and dephosphorylations of intracellular protein occurs, which include the MAPK/ERK, p38 $(19,20)$, and IKB $\alpha$ proteins $(13,14)$. The IKB $\alpha$, once phosphorylated, are degraded by cytoplasmatic proteases, enabling the translocation of NF$\kappa B$ into the nucleus $(21,22)$.

To study and characterize the effect of immune activation on T-cell signaling, we isolated PBMCs from 10 NA (Isr. and Eth.), 11 PA (Eth.), and 12 HA (Eth.) individuals and stimulated them with PMA and $\mathrm{Ca}^{2+}$ ionophore. At various time intervals after stimula- 
Table 1

Immune profile of studied populations

\begin{tabular}{|c|c|c|c|}
\hline & Isr. & new-Eth. & old-Eth. \\
\hline $\mathrm{CD}^{+}($cells $/ \mu \mathrm{l})$ & $853 \pm 44$ & $702 \pm 21.7^{A}$ & $749 \pm 41.6$ \\
\hline $\mathrm{CD}^{+}($cells $/ \mu \mathrm{l})$ & $638 \pm 34$ & $757 \pm 37.4$ & $566 \pm 28.4$ \\
\hline CD4/CD8 ratio & $1.38 \pm 0.07$ & $1.06 \pm 0.04^{\mathrm{A}}$ & $1.38 \pm 0.06$ \\
\hline Eosinophils (cells/ $\mu \mathrm{l}$ ) & $127 \pm 8.4$ & $748 \pm 58.6^{\mathrm{A}}$ & $322 \pm 40.7^{\mathrm{B}}$ \\
\hline $\lg \mathrm{E}(\mathrm{IU} / \mathrm{ml})$ & $105 \pm 23.3$ & $1650 \pm 125^{\mathrm{A}}$ & $203 \pm 31.5^{c}$ \\
\hline$\% \mathrm{HLA}^{-\mathrm{DR}^{+}} / \mathrm{CD}^{+}$ & $4.9 \pm 0.4$ & $10.3 \pm 0.75^{\mathrm{A}}$ & $5.9 \pm 0.55$ \\
\hline$\% \mathrm{HLA}^{\mathrm{DLR}}{ }^{+} / \mathrm{CD}^{+}{ }^{+}$ & $3.0 \pm 0.2$ & $6.4 \pm 0.35^{\mathrm{A}}$ & $4.2 \pm 0.36^{c}$ \\
\hline$\% \mathrm{HLA}^{-\mathrm{DR}^{+} / \mathrm{CD}^{+}}$ & $5.9 \pm 0.36$ & $13.4 \pm 0.84^{\mathrm{A}}$ & $9.6 \pm 0.92^{B}$ \\
\hline$\% \mathrm{CD} 4 \mathrm{RO}^{+} / \mathrm{CD}^{+}$ & $58.2 \pm 1.54$ & $68.3 \pm 1.09^{\mathrm{A}}$ & $65.2 \pm 1.5^{B}$ \\
\hline$\% \mathrm{CD} 5 \mathrm{RO}^{+} / \mathrm{CD}^{+}$ & $34.1 \pm 1.9$ & $31.1 \pm 1.5$ & $29.0 \pm 1.38$ \\
\hline$\% \mathrm{CD}^{4} 5 \mathrm{RA}^{+} / \mathrm{CD}^{+}$ & $35.2 \pm 2.2$ & $24.2 \pm 0.9^{\mathrm{A}}$ & $32.2 \pm 1.36$ \\
\hline$\% \mathrm{CD} 4 \mathrm{RA}^{+} / \mathrm{CD}^{+}$ & $65.8 \pm 2.46$ & $61.5 \pm 1.38$ & $69.8 \pm 1.36$ \\
\hline$\% \mathrm{CD}^{2} 8^{+} / \mathrm{CD}^{+}{ }^{+}$ & $55.7 \pm 2.8$ & $40.2 \pm 1.26^{\mathrm{A}}$ & $51.3 \pm 1.9$ \\
\hline
\end{tabular}

The results are the mean \pm SE obtained from 31, 111, and 48 Isr., new-Eth., and old-Eth. individuals, respectively. The significance of the difference between the Eth. groups and the Isr. group was determined by the Student's $t$ test. ${ }^{A} P<0.001 ;{ }^{B} P<0.01 ;{ }^{C} P<0.05$

tion, cell extracts were prepared and the presence or absence of phosphorylated or nonphosphorylated proteins was examined by Western blots as described in Methods. As shown in some representative examples in Figure 2a, PBMC extracts from all NA Eth. or Isr. individuals revealed strong phosphorylation of ERK isoforms (ERK1 and ERK2) upon stimulation. However, only attenuated phosphorylation of these kinases occurred in seven of $11 \mathrm{PA}$ and in 12 of $12 \mathrm{HA}$ Eth. individuals. The phosphorylation of ERK1 or ERK2 did not increase significantly over time in these examples (data not shown), and in some extreme cases, as shown in Figure 2b, almost no phosphorylation of ERK1 or ERK2 occurred even after prolonged times after stimulation. Moreover, the basal level of the nonphosphorylated ERK kinases, which was significantly higher in the NA Eth. than in the HA Eth. individuals, decreased upon stimulation in accordance with the very strong phosphorylation of ERK1 and ERK2 kinases (Figure 2b). In contrast, in the HA Eth. individuals, the basal levels of the nonphosphorylated ERK 1 did not change after stimulation and insignificant phosphorylation of ERK 1 or 2 occurred even 18 minutes after stimulation (Figure $2 b$ ).

In the case of PBMCs obtained from five Isr. individuals with an NA immune profile, the I $\mathrm{B} B \alpha$ proteins were degraded after cell stimulation as expected (Figure 3a). However, in PBMCs of the four HA Eth. individuals examined, the I $\mathrm{\kappa} \mathrm{B} \alpha$ proteins were not degraded, although they were partially phosphorylated after the cell stimulation (Figure 3a). Similar defective signaling occurred also in the p38 signal transduction pathway, as shown in a representative experiment in Figure 3b. In both NA and HA individuals, even without costimulation with $\mathrm{Ca}^{2+}$ ionophore and PMA, we found phosphorylated p38 in Western blot and FACS analyses, probably due to mechanical stress during the isolation of the cells. Nevertheless, fifteen minutes after the $\mathrm{Ca}^{2+}$ ionophore and PMA costimulation, no phosphorylated p38 was observed in five Isr. individuals examined (Figure 3b), indicating dephosphorylation by intracellular phosphatases. In contrast, no dephosphorylation of p38 kinase occurred in all five HA Eth. individuals examined (Figure $3 b$ ). In some experiments, as shown in a representative case in Figure 3c, only slight p38 phosphorylation occurred in the cell extracts from HA Eth. individuals; but in any case, no changes were noted after the cell costimulation by $\mathrm{Ca}^{2+}$ ionophore and PMA in these samples. Hence, we did not note p38 phosphorylation or dephosphorylation in the case of the HA Eth. individuals.

Analyses of the phosphorylation of phosphotyrosine kinases revealed a similar pattern of hyporesponsiveness in ten HA and PA Eth. individuals examined, as opposed to ten NA Eth. and NA Isr. individuals examined. In the case of NA individuals, a clear decrease of phosphorylated kinases was noted 3 minutes after the cell stimulation; thereafter, phosphorylated kinases continued to decrease in a somewhat lower rate. No such decrease was noted in the cell extracts obtained from activated individuals, indicating that they did not respond to the stimuli (Figure 4).

$\beta$-Chemokine secretion of $C D 8^{+}$cells after stimulation by phytohemagglutinin and PMA. The above signal transduction studies indicated altered capacity of PBMC obtained from immune-activated individuals to respond to stimuli, such as costimulation with $\mathrm{Ca}^{2+}$ ionophore and PMA. Measurement of $\beta$-chemokine secretion by $\mathrm{CD}^{+} \mathrm{T}$ cells stimulated for 48 hours with PMA and phytohemagglutinin (PHA), revealed a significantly lower secretion of RANTES and MIP- $1 \alpha$ from cells obtained from 23 HA and PA Eth. individuals than from cells obtained from 16 Isr. individuals $(27.8 \pm 11.9 \mathrm{ng} / \mathrm{ml}$ vs. $78.1 \pm 46.7 \mathrm{ng} / \mathrm{ml}$ of RANTES secretion; $P<0.0001$; and $95.5 \pm 38.3 \mathrm{ng} / \mathrm{ml}$ vs. 137.7 $\pm 48.9 \mathrm{ng} / \mathrm{ml}$ of MIP- $1 \alpha$ secretion; $P<0.02$ ).

Increased intracellular pool of CTLA-4 in the Eth. group. CTLA-4 is a CD28 homologue that serves as a negative regulator of T-cell responses $(23,24)$. Binding of $B 7$ to CTLA- 4 inhibits the CD28-dependent IL-2 production and proliferation $(23,25)$. Furthermore, ligation of CTLA-4 receptor by B-7 selectively shuts off activation of downstream T-cell receptor/CD28 signaling events, such as activation of ERK and JNK kinases (26). Resting memory cells, but not naive cells, contain intracellular supplies of CTLA-4 that are continuously recycled between the cytoplasm and the cell surface, raising the cells threshold for costimulatory signals (24). As PBMCs obtained from immune-activated Eth. individuals had decreased capacity to respond to stimuli, we examined whether they have increased expression of CTLA-4. Indeed, a comparison between CTLA-4 expression in 13 PA and HA Eth. and 24 NA Isr. subjects revealed significantly higher expression of CTLA- 4 in the Eth. than in the Isr. subjects $(8.47 \pm 1.97 \%$ vs. 5.29 $\pm 2.47 \%$ CTLA $-4^{+} \mathrm{CD} 4^{+}$cells, respectively; $P=0.03$ ).

$P B M C$ proliferation after stimulation with $P P D$, a recall antigen. On the basis of the fact that Eth. individuals 
lived in areas endemic to TB, we examined the capacity of PBMCs obtained from activated and nonactivated Eth. individuals to proliferate after stimulation with PPD, a TB-specific antigen. As shown in Figure $5 \mathrm{a}$, there is a significant, although weak, inverse correlation between the capacity of the cells to proliferate following PPD stimulation and the percentage of HLA-DR ${ }^{+} / \mathrm{CD}^{+}$cells. It should be noted that in all cases in which PBMCs were obtained from HA Eth. individuals, they proliferated poorly after PPD stimulation, and significantly less than in all other Eth. or PA individuals $(P<0.001$ and $P=0.038$, respectively, according to the Mann-Whitney rank sum test). Those that were able to respond significantly to the recall antigen were either NA or PA Eth. individuals.

As CTLA- 4 was elevated in Eth. compared with Isr. subjects (see earlier discussion), and as CTLA- 4 is a negative regulator of T-cell responses $(23,24)$ and upregulates the cell's threshold for costimulatory signals (24), we examined whether blocking of CTLA-4 with Fab mAb would enhance the proliferative responses to PPD of PBMCs obtained from Eth. subjects. Indeed, as depicted in Figure $5 \mathrm{~b}$, PBMCs obtained from seven of eight Eth. subjects proliferated significantly more strongly to PPD in the presence of $\mathrm{Fab} \mathrm{mAb}$ against CTLA-4.

DTH responses after intracutaneous PPD skin injections. DTH responses are part of the cell-mediated immunity. To study further the effect of immune activation on cellmediated immunity, DTH responses to PPD intracutaneous injection (Mantoux), were examined in 39 HA or PA Eth. individuals, heavily infested with helminthic parasites, before and 6 months after receiving antihelminthic treatment (albendazole). In addition, the presence of parasites in their stool was examined at both time points. Importantly, the DTH-positive responses to PPD in those individuals in whom the helminths were eradicated increased significantly after deworming, as opposed to those in whom the helminths were not eradicated $\left(P<0.004\right.$, McNemar's $\chi^{2}$ test $)$.

\section{Discussion}

Millions of individuals in the developing countries, especially in Africa, Southeast Asia, and South Ameri$\mathrm{ca}$, are infested with chronic infectious diseases, such as malaria, TB, protozoa and helminthic parasites, and HIV (1-3). The constant and lifelong confrontation of these hosts with such infectious burden results in a chronic immune activation and unbalanced immune state $(5,11,27,28)$. We have suggested that the capacity of such individuals to protect themselves and to cope with infections, as well as to mount protective immunity after vaccination, is highly impaired $(5,27)$.

The results of the present work strongly supports these suggestions by showing that chronic immune activation leads to hyporesponsiveness and anergy. This was manifested in highly immune-activated individuals by (a) defective or lacking of early transmembrane signaling (phosphorylation and/or dephosphorylation of tyrosine kinases), suggesting

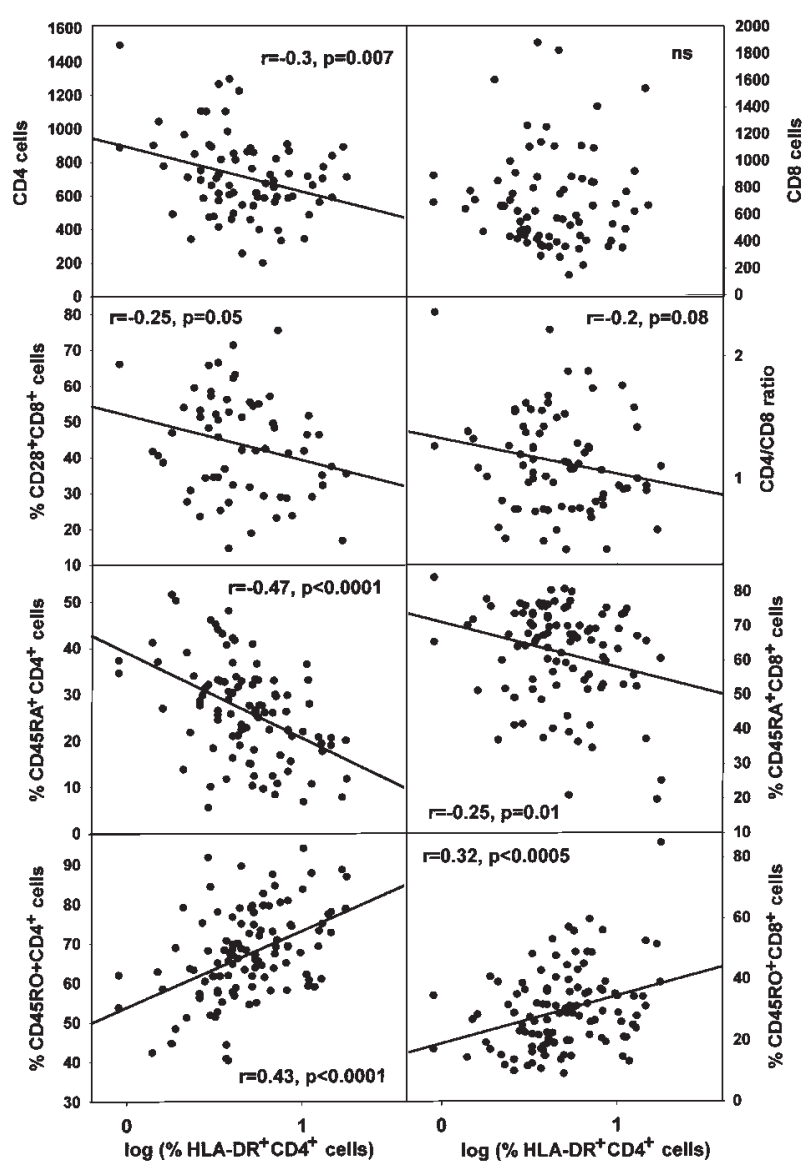

Figure 1

Correlations between the percentage of $\mathrm{HLA}-\mathrm{DR}^{+} \mathrm{CD} 4^{+}$cells and other cell subsets in Eth. individuals. ns, not significant.

malfunction of both kinases and phosphatases; (b) lack of degradation of phosphorylated I $\mathrm{B} \alpha$, indicating reduced or malfunction of a cellular protease(s); (c) lack or attenuated phosphorylation of downstream kinases, such as ERK and p38; (d) increased expression of CTLA-4, a downregulator protein; (e) decreased $\beta$-chemokine secretion of $\mathrm{CD}^{+}$cells after stimulation; (f) reduced capacity to proliferate after recall antigen stimulation; $(\mathrm{g})$ restoration of proliferative responses after CTLA-4 blocking; and (h) decreased DTH responses to recall antigen before deworming. These attenuated responses were not a reflection of slower kinetics, but represented significantly diminished responses. Hyporesponsiveness did not occur in only one signal transduction pathway, but in all those that we examined, indicating that this phenomena is a more general cell deficiency.

In concordance with these results are the following observations made by others: defective T-cell signaling occurs in patients with primary intracranial tumors (29); patients with malignant glioblastomas exhibit T-cell anergy (30); anergic Th1 murine cells have decreased p38 and ERK/MAPK activities, even though the levels of these proteins remain unchanged (31-33); and murine anergic $\mathrm{CD}^{+} \mathrm{T}$ cells are defective in their ability to 
Figure 2

Attenuated phosphorylation of ERK1 and ERK2 in chronically immune-activated individuals, as determined by Western blot analysis. PBMC extracts obtained from nonactivated (NA), highly activated (HA), or partially activated (PA) Eth. or Isr. individuals were stimulated for 0 or 6 minutes (a) or for $0,3,6,12$, and 18 minutes (b) with PMA and $\mathrm{CA}^{2+}$ ionophore. Lysates of these cells were resolved on SDSPAGE and immunoblotted with anti-phosphorylated p42/44 MAPK/ERK Ab $(1: 10,000)$ and anti-BCL2 Ab (1:500). The immunoblot in $\mathbf{b}$ was stripped and rehybridized with anti-p42/44 MAPK/ERK Ab (1:10,000). pERK, phosphorylated ERK.

upregulate protein binding and transactivation of the NF-AT and AP-1 transcription factors $(34,35)$.

$\mathrm{T}$-cell receptor stimulation in the absence of CD28mediated costimulation not only results in little IL-2 production, but induces a long-lasting hyporesponsive state known as T-cell clonal anergy (36). We have already found in several cohorts of Ethiopian immigrants to Israel that $\mathrm{CD} 28^{+}$expression on $\mathrm{CD}^{+}$cells was significantly reduced $(5-7,37)$. Also in the present work, the new- and old-Eth. cohorts studied had $30 \%$ and $10 \%$ lower expression of $\mathrm{CD} 28^{+} \mathrm{CD} 8^{+}$cells, respectively, than did the Isr. group. This lower expression of $\mathrm{CD}^{2} 8^{+}$on $\mathrm{CD}^{+}$cells was negatively correlated with HLA-DR expression in all T-cell subsets. Clearly, the reduced expression of this important costimulatory molecule in $\mathrm{T}$ cells in chronically immuneactivated individuals is detrimental to their capacity to mount immune responses.

Worsening the situation is the finding that the newEth. individuals studied had significantly less CD4 ${ }^{+}$ cells, less naive $\left(\mathrm{CD}^{2} 5 \mathrm{RA}^{+}\right)$cells, more memory $\left(\mathrm{CD} 45 \mathrm{RO}^{+}\right)$cells, and increased CTLA-4 expression on $\mathrm{CD}^{+}$cells than did the Isr. cohort. This is in accordance with our previous findings with other Eth. cohorts studied $(5-7,37)$. These differences were correlated with the activation of the individuals (as manifested by the percentage of $\mathrm{T}$ cells expressing the surface marker HLA-DR). Clearly, the diminished number of $\mathrm{CD}^{+}$cells and the lower percentage of naive cells in these individuals lessen their capacity to mount effective immune responses.

\section{Figure 3}

Impaired activation of $1 \kappa B \alpha$ and p38 in highly immune-activated individuals. PBMC extracts obtained from nonactivated (NA) Isr. and highly activated (HA) Eth. individuals were stimulated for 0 or 15 minutes with PMA and $\mathrm{CA}^{2+}$ ionophore. Lysates of these cells were resolved on SDS-PAGE and immunoblotted with (a) anti-IKB $\alpha$ $(1: 2,500)$ or with (b) anti-diphosphorylated p38 MAP kinase $(1: 1,000)$. (c) Kinetic analyses of the changes in p38 phosphorylation and dephosphorylation after stimulation. The cells were stimulated with PMA and $\mathrm{CA}^{2+}$ ionophore for $0,3,6$, or 12 minutes. As control, we activated jurkat cells.

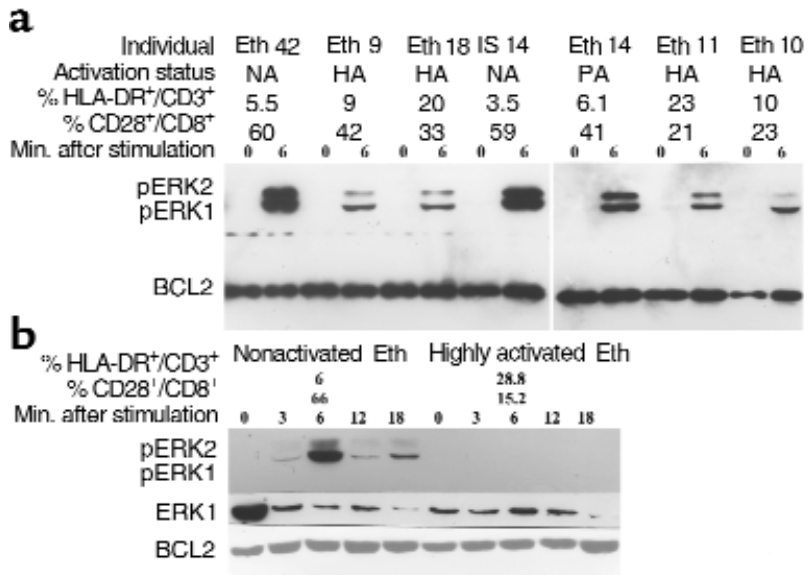

A Th2-like immune response with concomitant anergy and downregulation of Th1-associated immunity has been shown in mice infected with a helminthic parasite (38). To our knowledge, this is the first example showing in a human population that constant immune challenge results in a wide immune dysregulation, a predominant Th2 type of cytokine profile, and a clear impairment in the capacity of their cells to respond to stimuli. Taken together, our study strongly supports the idea that chronic immune activation leads to hyporesponsiveness and deficiency of the immune cells, and in some extreme cases to anergy, endangering not only the capacity of these individuals to cope with infection but with their capacity to mount an effective immune response after vaccination.

Several other observations also lend further support to this notion; for example (a) the very high incidence of TB in Africa despite the wide Bacillus CalmetteGuerin (BCG) vaccination carried out in this continent $(39,40)$; (b) the faster HIV disease progression in subSaharan Africa compared with the Western world (41, 42); (c) increased HIV plasma viral load, observed in helminth-infested regions in Africa (43), which was associated with Leishmaniasis and decreased after its treatment $(44,45)$; (d) human individuals, chronically infected with the filarial parasite Onchocerca vulvurus, have depressed cellular reactivity in vitro and deficient production of IL-2 in response to O. vulvurus-specific antigenic stimulation (46); and (e) humans infected with Schistosoma mansoni have impaired tetanus toxoidspecific immune responses (47).

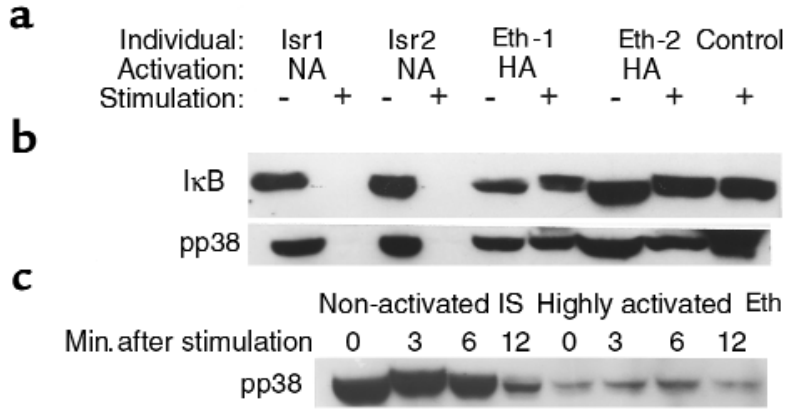




\section{Figure 4}

Differential changes in tyrosine phosphorylation in chronically immune-activated individuals compared with nonactivated controls. The patterns of tyrosine phosphorylation in PBMC cells were determined at various times after stimulation of the cells with PMA and $\mathrm{CA}^{2+}$ ionophore. Although after stimulation, clear changes in the tyrosine phosphorylation pattern occurred in NA individuals, no significant changes were
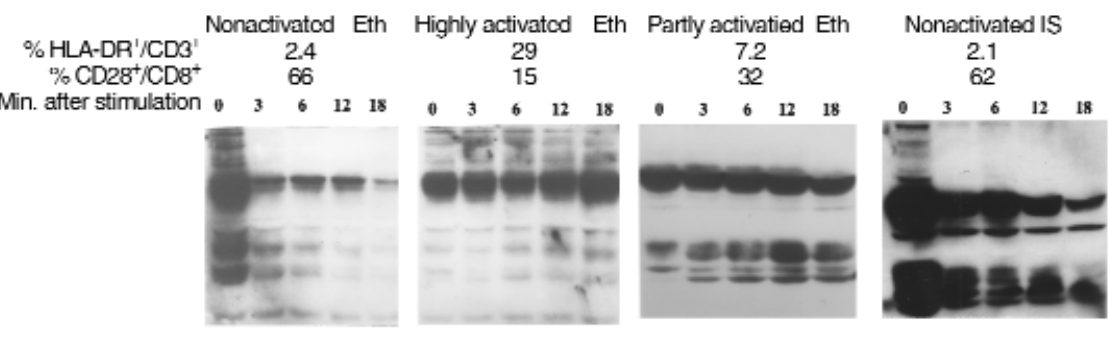
noted in the activated individuals

It should be noted that the expression of $\mathrm{CD} 28^{+}$on $\mathrm{CD}^{+}$cells, the $\mathrm{CD} 4 / \mathrm{CD} 8$ ratio, and the percentage of naive and memory cells, as well as the in vitro capacity to respond to stimuli, returns gradually to normal in Eth. individuals living for prolonged periods in Israel. Obviously, the change in environment, the better health care, nutrition, and so forth, and most importantly the eradication of the helminthic parasites, with which more than $80 \%$ of the new-Eth. immigrants were afflicted, contributed to this improvement in the immune system of these individuals.

It is believed that generation of HIV- or M. tuberculosis-specific cellular immunity by a vaccine, via a Th1 immune response, is a major prerequisite for any protective HIV or M. tuberculosis vaccine (48-50). The highest incidence of both $M$. tuberculosis and HIV infections are in Southeast Asia and Africa (2,3). It is clear that the efficacy of HIV and TB candidate vaccines will have to be tested in human field trials that can only take place in Africa and Asia, in areas with a high incidence of HIV and M. tuberculosis infections. However, potentially good vaccines may fail in such clinical trial if examined in the immune scenario presently existing in the developing world. It is quite clear that the host immune background in developing countries is biased toward a Th2 profile and that most individuals are in a chronic immune-activation state, similar to that which we have seen in the Eth. group. Our findings that signal transduction in such individuals is impaired and that their immune cells can respond poorly to stimuli, such as to PPD, suggest that their capacity to elicit an immune response

\section{Figure 5}

(a) Diminished proliferation to PPD antigen by cells obtained from $\mathrm{HA}$ individuals. PBMCs were incubated for 6 days with or without 5 $\mu \mathrm{g} / \mathrm{ml}$ PPD and then pulsed with $\left[{ }^{3} \mathrm{H}\right]$ thymidine. The log of SI (stimulation index: incorporation of $\left[{ }^{3} \mathrm{H}\right]$ thymidine in the presence of PPD divided by the amount of $\left[{ }^{3} \mathrm{H}\right]$ thymidine incorporated in the presence of medium alone) is plotted against the log of percentage of HLA-DR expression on the CD3+ cells. (b) Enhancement of proliferation to PPD after blockage of CTLA-4. PBMCs were stimulated with PPD (as in a, above) in the presence of $0.13 \mu \mathrm{g}(0.66 \mu \mathrm{g} / \mathrm{ml})$ Fab $\mathrm{mAb}$ against CTLA- 4 or matched Fab isotype mAb control. The stimulation index results are the average of triplicates. after vaccination will be heavily encumbered. The failure of BCG vaccination in Africa and Asia to confer protective immunity to $\mathrm{TB}$ clearly supports this assumption. It therefore becomes essential to take this major issue into consideration for any protective vaccine development. The simplest and most effective way to do so is by eradication of helminthic infections before or during vaccination. Such eradication is important by itself and has clear advantages and benefits regardless of the issue of HIV and TB vaccination, such as the capacity to cope with infections, the capacity to learn, and so on. We suggest that deworming will have a huge impact on the capacity of individuals in the developing world to cope with disease, and more importantly, we believe that without eradication of helminths, HIV and TB vaccines, and probably others, may fail to confer protection in helminth endemic areas.
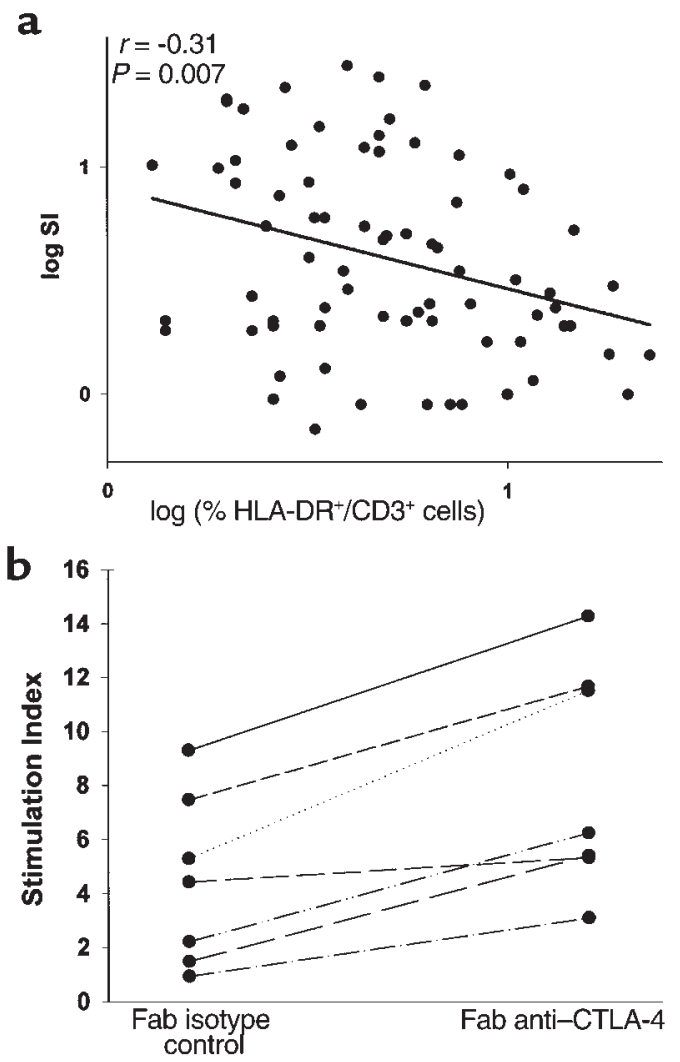


\section{Acknowledgments}

The work was supported in part by the grants from The Institute of Advanced Therapy (IAT) for Center of Excellence in AIDS Research in Israel, and the Horowitz Foundation, granted to the Kaplan AIDS Center. A. Kalinkovich is a KAMEA fellow.

1. Chan, M.S. 1997. The global burden of intestinal nematode infections fifty years on. Parasitol. Today. 13:438-443.

2. Dye, D., Scheele, S., Dolin, P., Pathania, V., and Raviglione, M.C. 1999 Global burden of tuberculosis: estimated incidence, prevalence, and mortality by country. JAMA. 282:677-686

3. Satcher, D. 1999. The global HIV/AIDS epidemic. JAMA. 281:1479.

4. Nahmias, J., et al. 1993. Health profile of Ethiopian immigrants in Israel: an overview. J. Isr. Med. Sci. 29:338-343.

5. Bentwich, Z., Kalinkovich, A., and Weisman, Z. 1995. Immune activation is a dominant factor in the pathogenesis of AIDS in Africa. Immunol. Today. 16:187-191.

6. Bentwich, Z., Weisman, Z., Moroz, C., Bar-Yehuda, S., and Kalinkovich, A. 1996. Immune dysregulation in Ethiopian immigrants to Israel: relevance to helminth infections? Clin. Exp. Immunol. 103:239-243.

7. Kalinkovich, A., et al. 1998. Decrease CD4 and increased CD8 counts with T-cell activation is associated with chronic helminth infection. Clin. Exp. Immunol. 114:414-421.

8. Messele, T., et al. 1999. Reduced naive and increased activated CD4 and CD8 cells in healthy adult Ethiopians compared with their Dutch counterparts. Clin. Exp. Immunol. 115:443-450.

9. Freedman, D.O., Lujan-Trangay, A., Steel, C., Gonzalez-Peralta, C., and Nutman, T.B. 1991. Immunoregulation in onchocerciasis. Functional and phenotypic abnormalities of lymphocyte subsets and changes with therapy. J. Clin. Invest. 88:231-238.

10. Maizels, R.M., Bundy, D.A.P., Selkirk, M.E., Smith, D.F., and Anderson, R.M. 1993. Immunological modulation and evasion by helminth parasites in human populations. Nature. 365:797-805

11. Kalinkovich, A., Maayan, S., Weisman, Z., Harpaz, N., and Bentwich, Z 1994. Immune activation, a co-factor for HIV transmission in Thailand? Lancet. 343:1506-1507.

12. Rizzardini, G., et al. 1996. Immunological activation markers in the serum of African and European HIV-seropositive and seronegative individuals. AIDS. 10:1535-1542.

13. Rizzardini, G., et al. 1998. Immune activation in HIV-infected African individuals. AIDS. 12:2387-2396.

14. Nahmias, J., Greenberg, Z., Djerrasi, L., and Giladi, L. 1991. Mass treatment of intestinal parasites among Ethiopian immigrants. Isr. J. Med. Sci 27:278-283.

15. Bentwich, Z., Weisman, Z., Grossman, Z., Galay, N., and Kalinkovich, A. 1997. Pathogenesis of AIDS in Africa: lessons from the Ethiopian immigrants in Israel. Immunologist. 5:211-226.

16. Linsley, P.S., and Ledbetter, J.A. 1993. The role of CD28 receptor during T cell responses to antigen. Annu. Rev. Immunol. 11:191-212.

17. Su, B., et al. 1994. JNK is involved in signal integration during costimulation of T lymphocytes. Cell. 77:727-736.

18. Wulfing, C., and Davis, M.M. 1998. A receptor/cytoskeletal movement triggered by costimulation during $\mathrm{T}$ cell activation. Science. 282:2266-2269.

19. Seger, R., and Krebs, E.G. 1995. The MAPK signaling cascade. FASEB J. 9:726-735.

20. Cano, E., and Mahadevan, L.C. 1995. Parallel signal processing among mammalian MAPKs. Trends Biochem. Sci. 20:117-122.

21. Beg, A.A., and Baldwin, A.S. 1993. The IkB proteins: multifunctional regulators of the Rel/NF-kB transcription factors. Genes Dev. 7:2064-2070.

22. Karin, M., and Ben-Neriah, Y. 2000. Phosphorylation meets ubiquitination: the control of NF-kappaB activity. Annu. Rev. Immunol. 18:621-663.

23. Walunas, T.L, Bakker, C.Y., and Bluestone, J.A. 1996. CTLA-4 ligation blocks CD28-dependent T cell activation. J. Exp. Med. 183:2541-2550.

24. Metz, D.P., Farber, D.L., Taylor, T., and Bottomly, K. 1998. Differential role of CTLA-4 in regulation of resting memory versus naive CD4 T cell activation. J. Immunol. 161:5855-5861.
25. Krummel, M.F., and Allison, J.P. 1996. CTLA-4 engagement inhibits IL2 accumulation and cell cycle progression upon activation of resting $\mathrm{T}$ cells. J. Exp. Med. 183:2533-2540.

26. Calvo, C.R., Amsen, D., and Kruisbeek, A.M. 1997. Cytotoxic T lymphocyte antigen 4 (CTLA-4) interferes with extracellular signal-regulated kinase (ERK) and Jun NH2-terminal kinase (JNK) activation, but does not affect phosphorylation of T cell receptor zeta and ZAP70. J. Exp. Med. 186:1645-1653

27. Bentwich, Z., et al. 1999. Can eradication of helminthic infections change the face of AIDS and tuberculosis? Immunol. Today. 20:485-487.

28. Desjeux, P. 1966. Leishmaniasis: public aspects and control. Clin. Dermatol. 14:417-423.

29. Morford, L.A., Elliott, L.H., Carlson, S.L., Brooks, W.H., and Roszman, T.L. 1997. T cell receptor-mediated signaling is defective in T cells obtained from patients with primary intracranial tumors. J. Immunol. 159:4415-4425.

30. Mahaley, M.S., Jr., et al. 1977. Immunobiology of primary intracranial tumors. Part 1: studies of the cellular and humoral general immune competence of brain-tumor patients. J. Neurosurg. 46:467-476.

31. Fields, P.E., Gajewski, T.F., and Fitch, F.W. 1996. Blocked Ras activation in anergic CD4+ T cells. Science. 271:1276-1278.

32. DeSilva, D.R., Feeser, W.S., Tancula, E.J., and Scherle, P.A. 1996. Anergic $T$ cells are defective in both jun NH2-terminal kinase and mitogen-activated protein kinase signaling pathways. J. Exp. Med. 183:2017-2023.

33. DeSilva, D.R., Jones, E.A., Feeser, W.S., Manos, E.J., and Scherle, P.A. 1997. The p38 mitogen-activated protein kinase pathway in activated and anergic Th1 cells. Cell. Immunol. 180:116-123.

34. Li, W., Whaley, C.D., Mondino, A., and Mueller, D.L. 1996. Blocked signal transduction to the ERK and JNK protein kinases in anergic CD4+ T cells. Science. 271:1272-1276.

35. Mondino, A., et al. 1996. Defective transcription of the IL-2 gene is associated with impaired expression of c-Fos, FosB, and JunB in anergic T helper 1 cells. J. Immunol. 157:2048-2057.

36. Powell, J.D., Ragheb, J.A., Kitagawa-Sakakida, S., and Schwartz, R.H. 1998. Molecular regulation of interleukin-2 expression by CD28 co-stimulation and anergy. Immunol. Rev. 165:287-300.

37. Weisman, Z., et al. 1999. Infection by different HIV subtypes (B and C) results in a similar immune activation profile despite distinct immune backgrounds. J. Acquir. Immune Defic. Syndr. 21:157-163.

38. Villa, O.F., and Kuhn, R.E. 1996. Mice infected with the larvae of Taenia crassiceps exhibit a Th2-like immune response with concomitant anergy and downregulation of Th1-associated phenomena. Parasitology. 112:561-570.

39. Orme, I.M. 1995. Prospects for new vaccines against tuberculosis. Trends Microbiol. 3:401-404.

40. Fine, P.E. 1998. Vaccines, genes and trials. Novartis. Found. Symp. 217:57-72.

41. Gilks, C.F. 1993. The clinical challenge of the HIV epidemic in the developing world. Lancet. 342:1037-1039.

42. Anzala, O.A., et al. 1995. Rapid progression to disease in African sex workers with human immunodeficiency virus type 1 infection. J. Infect. Dis. 171:686-689.

43. Dyer, J.R. 1998. High levels of human immunodeficiency virus type 1 in blood and semen of seropositive men in sub-Saharan Africa. J. Infect. Dis. 177:1742-1746

44. Preiser, W., et al. 1996. Immunological findings in HIV-Leishmania coinfection. Intervirology. 39:285-288.

45. Berhe, N., et al. 1999. HIV viral load and response to antileishmanial chemotherapy in co-infected patients. AIDS. 13:1921-1925.

46. Galin, M., et al. 1988. Cell-mediated immune responses in human infection with Onchocerca volvulus. J. Immunol. 140:1999-2007.

47. Sabin, E.A., Araujo, M.I., Carvalho, E.M., and Pearce, E.J. 1996. Impairment of tetanus toxoid-specific Th1-like immune responses in humans infected with Schistosoma mansoni. J. Infect. Dis. 173:269-272.

48. Harboe, M. 1998. Protective immunity to intracellular parasites: a focus for vaccine research and a challenge to immunization programmes. Dev. Biol. Stand. 92:145-147.

49. Heilman, C.A., and Baltimore, D. 1998. HIV vaccines: where are we going? Nat. Med. 4:532-534.

50. Burton, D.R., and Moore, J.P. 1998. Why do we not have an HIV vaccine and how can we make one? Nat. Med. 4:495-498. 